\title{
Conceptualizing the Causal Chain of Technostress, Knowledge Sharing and Research Performance
}

\author{
Khuzaini $^{1}$, Zakky Zamrudi ${ }^{2}$, Rahmi Widyanti ${ }^{3}$, Dwi Wahyu Artiningsih ${ }^{4}$, Farida Yulianti ${ }^{5}$ \\ Universitas Islam Kalimantan, Muhammad Arsyad Al Banjari, Banjarmasin 1,2,3,4,5
}

\{zakky@uniska-bjm.ac.id²\}

\begin{abstract}
The rise of technology has brought many conveniences both for enduser, business, and academia. The benefit perceived by academia is that the lack of information update is no longer a vital problem in research. The ease of technology creates the fast delivery of information, makes the research is internationally disseminated and reached. The researcher task is now can be conducted remotely removing the time and space barriers. However, this condition also brings a significant consequence on the job stress that transforms into technostress caused by the arousing of technology. This study is aimed to conceptualize the maps of technostress among employee and the knowledge sharing to reduce the technostress among researcher and at the same time increasing the research and organizational performance. The finding in this paper emphasizes the antecedent, moderating, and output variable of the causal chain in research performance.
\end{abstract}

Keyword : Technostress, Knowledge, Performance.

\section{Introduction}

The progress of information technology has increased over the past decade. Information and communication technology (ICT) is the most commonly used technology in work and in everyday life and the deep connections that cause this technology to cause unclear work at home [1]. Although the use of ICTs has significantly increased the effectiveness and efficiency of organizations, it also creates technical pain for staff. It related to the volume of domestic work, increased work-home conflicts, violations of privacy, continuous learning and those related to unsafe work [2]-[4]. Technical pain has shown able to increase fatigue in the workplace and reducing employee effectiveness [3], [5]. Job fatigue is a psychological symptom of emotional exhaustion caused by chronic stress in the workplace for a long time and leads to personal inefficiency [6], [7]. Fatigue in the workplace is not only related to negative results, but only to organizations, but also includes individuals who express depression, feelings of failure, fatigue or loss of motivation [8], [9]. Many international organizations, such as the International Labour Organization and the World Health Organization, are concerned that the tension caused by the use of ICTs affects the health of employees [10]

This study aimed to review and propose a model to understand existing technostress faced by academic society by combining various sources in the area of information technology. 
Various literature from main topics of human-computer interaction, digital communication, knowledge management systems, personal behavioural theories and social, behavioural theories was combined and compiled to highlight any critical discussions. The value of the present study lies in the formulation of a systematic review. A systematic review is aimed at highlighting, group and stipulate the dimension and construct that may have a causal-chain between technostress, knowledge sharing and research performance. The grouped dimension and construct then graphed into a conceptual framework proposed to measure research performance among scientist. The proposed framework is expected to ease the researcher in defining the empirical research design, further meta-analysis design, research roadmaps and stimulate any further potential ideas in this subject area.

Indonesia is one of a developing country that is currently focusing on developing human resource by empowering research and development (R\&D) capabilities. Ministry of research, technology and higher education as the chief policymaker, which regulates the research policy in Indonesia has launched various programs to advance the research outputs. It includes several online apps for research purposes. However, the results of technostress in academic are limited. Thus this research is trying to adopt several constructs taken from various research in both academic and non-academic study-case to create the model.

The following paper is organized by formulating the research question formulation, which stated in the previous paragraph. The next step will specify the research method used in this study briefly. The compiled data from prior studies then will explain the exhaustive proposed model of technostress and knowledge sharing. The final step reserves the concluding remarks and limitation of present studies.

\section{Methodology}

This research is aimed to build a conceptual model of existing phenomena in Indonesia reviewing the current research information systems provided by ministry of research and higher education on Indonesia to help lecturer and scientist. The literature search was executed on science platform from ScienceDirect while the file management was employing the help of Mendeley software. As the research interest covers both social and natural science, the papers selection was based on the area of social and natural science. The term was used in this paper was most commonly coming from the literature related to job stress, the scientist performance indicators, and knowledge management focusing on knowledge sharing. Due to limited source on knowledge sharing and the relation on the technostress, this research spans the searching criteria from 2008 to 2019 resulting 29 paper related to the proposed topics.

The review process is based on qualitative analysis by using a systematic review. Searching for related documents in this process has not been completed by using PRISMA principle [11]. But this discovery can be used as a summary of current studies. A total amount of 25 studies were selected for in-depth analysis. Only the articles in the journals included in our study; conference documents, doctoral manuscript, and textbooks, as we believe that the articles in the nominated journals represent the latest research results [12], [13].

The focus of this study is on the documentation, which shows empirical studies in the applied variables and will examine the recommended patterns and incorporate them into our cause framework. The steps were started from criteria selection by reading the team were asked to confirm if the referenced paperwork has a strong relation with the topic being studied. The criteria were mainly evaluated from keywords, abstract, model evaluated inside the paper or related proposition. 


\section{Result and Discussion}

\subsection{Theories and Model}

There are various background of studies in order to help formulate the appropriate research construct. The background study involved in this study is including the human computer interaction, technology acceptance model (TAM), and workplace psychology.

\subsection{Causal Chain of Technostress Among Lecturer}

A causal chain framework were develop to emphasize the relationship of lecturer and researcher performance regarding the dynamic changes of systems development. The systems is aimed to measure the lecturer and researcher performance which somehow creates such a stress caused by technology on their performance. The causal chain framework were depicted by figure 1 , while the relationship development is used to determine the antecedent, mediating and outcomes is described as follows.

\subsubsection{Antecedent}

The existing causal-chain framework includes the stimuli factors that precede the behaviour results locate as the input of the structure. This stimuli factor are also commonly called as an exogenous variable. In the existing literature of research performance, the exogenous variable is consisting of two primary constructs, namely technostress and knowledge sharing.

\section{a) Technostress}

In terms of technostress most of researcher proposing the existing factors that is comprises of techno-overload, techno-invasion, techno-complexity, techno-security, and technouncertainty. The factors were built from the behavioural theories. The built dimension is aimed to measure the factor of personal perception after the rise of technology development that is aimed to help the research tasks, but it gives a stress during the works [14]-[16].

\section{b) Knowledge Sharing}

According to the theory of social capital, social capital is an integrated asset with social networks. This can foster and develop collaborative relationships among members of the organization [17]. This allows the team to have more than one person working in isolation. This concept is used to share knowledge and collaborative research in the workplace. Social relationships can be divided into strong or weak bonds: strong bonds are a close relationship between people, and weak bonds are weak bonds [18].

\subsubsection{Mediators}

Mediators are defined as intervening variables that explain the causal relationships between antecedents, mediators, and outcomes (Preacher, Rucker, \& Hayes, 2007). A 
complete mediation is considered by a whole intervention caused by mediator's variable. The mediator variables in this study are knowledge sharing and organizational commitment.

\section{a) Knowledge Sharing}

The rise of techno stress is somehow creating the society to make a discussion either in personal discussion or through a discussion group to ease the access and use of technology in order to help the research process . This process creates new stream that at least three factors that is coopetition, general knowledge-sharing, and specific knowledge sharing [18]-[22]. The knowledge sharing is expected to risen the personal performance in research that will eventually increase the organizational performance.

\section{b) Organizational Commitment}

Previous studies on technostress is commonly uses organisational outcomes such as productivity, task-performances, and organisational commitment [23]. The organizational commitment on the employees is could be positively increased or interfered by the dynamic and complex system use which is known by the techno-uncertainty. Researcher needs to focus on developing the research while it has to focus on the performance appraisal systems that can change their performance [9].

\subsubsection{Outcomes}

The outcomes variable is defined as the expected results by antecedents by the intervention of mediators. The outcomes variable are commonly called as an endogenous variable. The outcomes variable in this study is personal performance and organizational performance.

\section{Personal Performance \& Organizational Performance}

Personal performance is an important factor that influences organizational performance [1]. In an educational environment, the work of a lecturer is a strategic and key factor that determines student performance and academic performance at a university [24]. Studying the factors that influence the work of teachers in higher education institutions from different environments not only helps enrich and improve theory, but also provides sensible suggestions for improving the quality of work of higher education institutions. Worker participation is mainly in the industrial and commercial sectors, but has recently appeared in schools [2].

Table 1. Attributes adoption in technostress

\begin{tabular}{lcc}
\hline \multicolumn{1}{c}{ Attributes } & Reference & N of studies \\
\hline Antecedent & {$[14]-[16]$} & \\
1. Technostress & {$[17],[18],[25]$} & 3 \\
2. Knowledge Sharing & {$[18]-[22]$} & 3 \\
Mediators & {$[6],[8],[9],[24]$} & 5 \\
1. Technostress & 4 \\
2. Organizational Commitment & {$[1],[3],[24],[26]-[28]$} & 4 \\
Outcomes & {$[1],[6],[18],[27]-[30]$} & 7 \\
1. Personal performance & \\
2. Organizational performance & . & \\
\hline
\end{tabular}




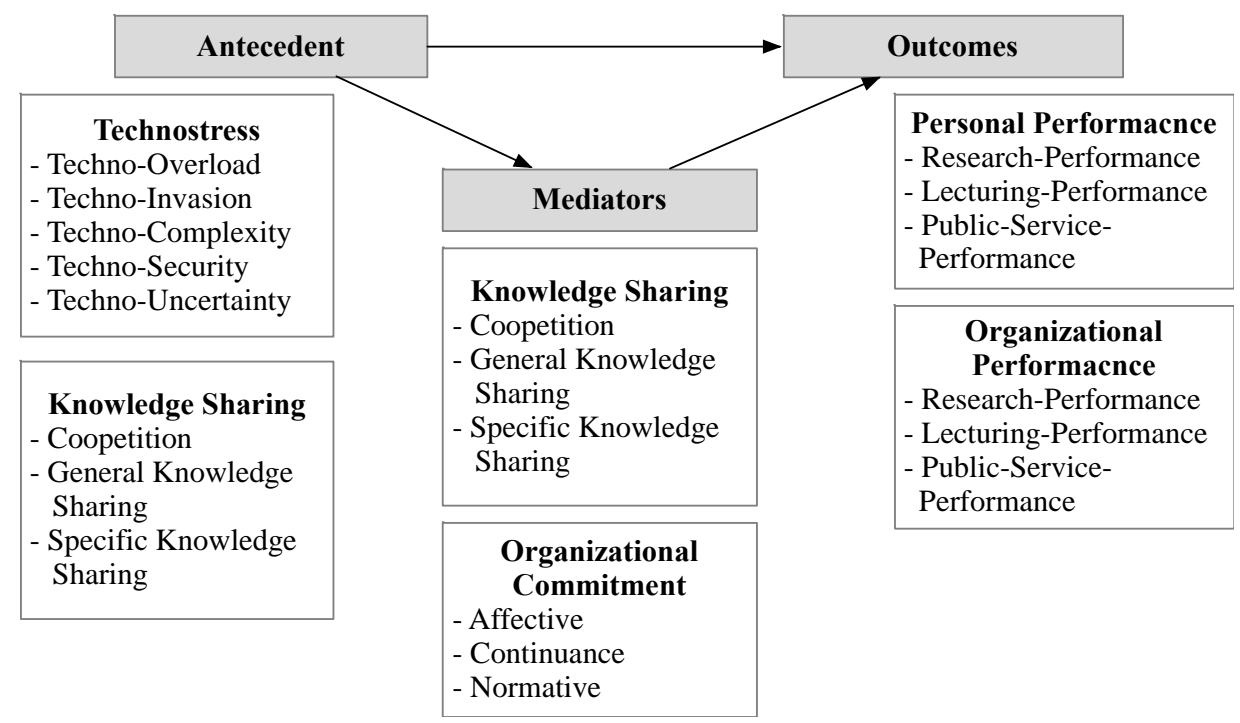

Fig. 1. Causal chain framework of techno-stress and knowledge sharing related

\section{Conclusion}

The researcher performance is essential for the country development. The better the research conducted in one country indicates a better improvement in human development index. By using this research, it is expected that the human resource capability in a particular country is increased to support economic development by using various aspect. This study aimed to identify the technostress and job performance by research colleagues in Indonesia. The expected result is a conceptual model to measures job performance and its relation of technostress and knowledge sharing among scientist in Indonesia.

The sample article in this study emphasizes various research construct in the area of technostress and factor that may reduce or increase the stressor. The various study concludes that to reduce the technostress is by using knowledge sharing among scientist. The barriers to limited knowledge could be reduced by using knowledge sharing. There is a recursive relation between knowledge sharing and technostress. However, to know the most potent relationship could be done by using empirical data. By identifying the stress-reduction factor relationship, it is expected that the finding can give a practical contribution to remove the barriers widely across the archipelago.

The contribution of current research is used as the primary reference for future research in measuring the research performance of Indonesia scientist. Qualitatively this research conducts a literature analysis of 25 research paper in the area of technostress, knowledge sharing and research performance. The results are including the classification of antecedent, mediators and outcomes variable. In the antecedent, there is two variable namely technostress and knowledge sharing; mediator variable consists of two variable namely knowledge sharing and organizational commitment; outcomes variable consist of two variable namely organizational performance and personal performance. Some of the antecedent variables also act as mediators. The knowledge sharing is also a mediator's variable between technostress and personal \& organizational performance. 
However, this research was constructed and interpret with several limitations. First, this result of the study may not inherit the exhaustive topics in the area of technostress. The reason is that there is limited literature in the area of technostress and knowledge sharing. Most of the technostress is describing the phenomena of technostress and the stress-reducer but limited in including knowledge sharing as a stress reliever. Second, there is a need to include the research roadmap to conclude the current research for the future research agenda. Finally, future study is suggested to future research to enrich the research area by using both using empirical data or secondary data arouse from various research metrics such as journal indexing metrics.

\section{References}

[1] M. Tarafdar, Q. Tu, and T. S. Ragu-Nathan, "Impact of Technostress on End-User Satisfaction and Performance,” J. Manag. Inf. Syst., vol. 27, no. 3, pp. 303-334, 2010.

[2] M. Tarafdar, Q. Tu, T. S. Ragu-Nathan, and B. S. Ragu-Nathan, "Crossing to the dark side," Commun. ACM, vol. 54, no. 9, p. 113, 2011.

[3] S. C. Srivastava, S. Chandra, and A. Shirish, "Technostress creators and job outcomes: Theorising the moderating influence of personality traits," Inf. Syst. J., vol. 25, no. 4, pp. 355-401, 2015.

[4] I. Gede Eko Putra Sri Sentanu, Z. Zamrudi, and A. Praharjo, "Consumer Generated Media: Understanding Indonesian Social Traveller," in Journal of Physics: Conference Series, 2019, vol. 1175, no. 1.

[5] Ayyagari, Grover, and Purvis, "Technostress: Technological Antecedents and Implications," MIS Q., vol. 35, no. 4, p. 831, 2011.

[6] E. Brivio et al., "Preventing technostress through positive technology," Frontiers in Psychology, vol. 9, no. DEC. Frontiers, p. 2569, 17-Dec-2018.

[7] Z. Zamrudi, S. Karim, M. Faridha, D. Maharani, and A. D. Kuraesin, "Smart meter adoption: The role of consumer experience in using smart device," in Journal of Physics: Conference Series, 2019, vol. 1175, no. 1.

[8] R. K. Jena, "Technostress in ICT enabled collaborative learning environment: An empirical study among Indian academician," Comput. Human Behav., vol. 51, 2015.

[9] U. N. U. Ahmad, S. M. Amin, and W. K. W. Ismail, "The Relationship Between Technostress Creators and Organisational Commitment Among Academic Librarians," Procedia - Soc. Behav. Sci., vol. 40, pp. 182-186, Jan. 2012.

[10] A. Mahboob, “Technostress and Its Management Techniques: A Literature Review," J. Hum. Resour. Manag., vol. 4, no. 3, p. 28, 2016.

[11] D. Moher, A. Liberati, J. Tetzlaff, and D. G. Altman, "Preferred Reporting Items for Systematic Reviews and Meta-Analyses: The PRISMA Statement," Ann. Intern. Med., vol. 151, no. 4, p. 264, Aug. 2009.

[12] Y. Y. Y. Chan and E. W. T. Ngai, "Conceptualising electronic word of mouth activity," Mark. Intell. Plan., 2011.

[13] E. W. T. Ngai and F. K. T. Wat, "Ngai2002.Pdf," vol. 39, pp. 415-429, 2002.

[14] U. N. U. Ahmad and S. M. Amin, "The Dimensions of Technostress among Academic Librarians," Procedia - Soc. Behav. Sci., vol. 65, pp. 266-271, Dec. 2012.

[15] D. M. Marchiori, E. W. Mainardes, and R. G. Rodrigues, "Do Individual Characteristics Influence the Types of Technostress Reported by Workers?," Int. J. Hum. Comput. Interact., vol. 35, no. 3, pp. 218-230, 2018. 
[16] H. Ibrahim and Y. M. Yusoff, "User Characteristics as Antecedents of Techno Stress towards EHRM: From Experts' Views," Procedia - Soc. Behav. Sci., vol. 172, pp. 134 141, Jan. 2015.

[17] Nuryakin, R. W. PA, and I. Fatmawati, "Network Advantage: Mediating Effect on Business Performance," Sci. Ann. Econ. Bus., vol. 65, no. 4, pp. 443-457, Dec. 2018.

[18] F. Ghabban, A. Selamat, and R. Ibrahim, "New model for encouraging academic staff in Saudi universities to use IT for knowledge sharing to improve scholarly publication performance," Technol. Soc., vol. 55, pp. 92-99, 2018.

[19] J. Gast, K. Gundolf, R. Harms, and E. Matos Collado, "Knowledge management and coopetition: How do cooperating competitors balance the needs to share and protect their knowledge?," Ind. Mark. Manag., vol. 77, no. October 2018, pp. 65-74, 2019.

[20] S. L. Kim, M. Kim, and S. Yun, "Knowledge Sharing, Abusive Supervision, and Support: A Social Exchange Perspective," Gr. Organ. Manag., vol. 40, no. 5, pp. 599624, 2015.

[21] M. Dokhtesmati and R. G. Bousari, "Knowledge Sharing in Iranian Academic Institutions: Meta Analysis Approach," Procedia - Soc. Behav. Sci., vol. 73, pp. 383 387, Feb. 2013.

[22] N. Ganapathi and N. Panchanatham, "Workplace Stress: The need for Communication and Knowledge Sharing," Int. J. Exclus. Manag. Res., vol. 2, no. 2, pp. 1-15, 2012.

[23] M. Tarafdar, Q. Tu, B. S. Ragu-Nathan, and T. S. Ragu-Nathan, "The Impact of Technostress on Role Stress and Productivity,” J. Manag. Inf. Syst., vol. 24, no. 1, pp. 301-328, 2007.

[24] D. S. Sukirno and S. Siengthai, "Does participative decision making affect lecturer performance in higher education?," Int. J. Educ. Manag., vol. 25, no. 5, pp. 494-508, 2011.

[25] M. Hajli, M. Hajli, and F. Khani, "Establishing trust in social commerce through social word of mouth," Int. J. Inf. Sci. Manag., vol. 11, no. SPL.ISS., pp. 39-53, 2013.

[26] S. Brooks, "Does personal social media usage affect efficiency and well-being?," Comput. Human Behav., vol. 46, pp. 26-37, 2015.

[27] S. Brooks and C. Califf, "Social media-induced technostress: Its impact on the job performance of it professionals and the moderating role of job characteristics," Comput. Networks, vol. 114, pp. 143-153, 2017.

[28] M. L. Yu, S. Hamid, M. T. Ijab, and H. P. Soo, "The e-balanced scorecard (e-BSC) for measuring academic staff performance excellence," High. Educ., vol. 57, no. 6, pp. 813-828, 2009.

[29] T. Rashid and H. M. Asghar, "Technology use, self-directed learning, student engagement and academic performance: Examining the interrelations," Comput. Human Behav., vol. 63, pp. 604-612, 2016.

[30] K. Wang, Q. Shu, and Q. Tu, "Technostress under different organizational environments: An empirical investigation," Comput. Human Behav., vol. 24, no. 6, pp. 3002-3013, 2008. 